\title{
From Venture Idea to Venture Formation: The Role of Sensemaking, Sensegiving \& Sense receiving
}

\begin{abstract}
This article explores the sensemaking processes entrepreneurs use when transitioning between venture ideas and venture formation. Adopting a sensemaking/sensegiving approach and utilising an interpretivist methodology, we use sensemaking to analyse the entrepreneurial journey of four diverse entrepreneurs. In so doing, we make three contributions: first, we locate the early stages of the entrepreneurial context as a primary site where sensemaking occurs as entrepreneurs deal with the differences between expectations and reality. Second, we show how sensemaking occurs when entrepreneurs build a causal map of the problem they wish to address and how social exchanges are crucial as entrepreneurs then refine that idea with other sensegivers. Finally, we extend scholarly understanding through explaining the ways in which sensemaking, sensegiving and sense receiving contribute to the entrepreneurs' decision to act and create a new venture.
\end{abstract}

\section{INTRODUCTION}

Calls for a renewed focus on the processual nature of entrepreneurship have resulted in attempts to clarify the early stages of the venture creation process (Vogel, 2017; McMullen \& Dimov, 2013; Venkataraman, Sarasvathy, Dew \& Forster, 2012). Understanding how an entrepreneur transitions between the venture idea and venture formation appears fundamental yet, few studies have followed the process of entrepreneurial action between having a venture idea and forming a venture (George \& Bock, 2012; Garud \& Giuliani, 2013). Even fewer have examined the sensemaking happening during this transition period (Gartner, Carter \& Hill, 2016).

Sensemaking is significant given its contribution to analysing human behaviour in times of uncertainty (Weick, Sutcliffe \& Obstfeld, 2005). As a cognitive process, sensemaking is the primary site where meanings materialise that inform and constrain action (Mills, 2003). Existing research on sensemaking in the entrepreneurial process has focused on its role as a socially embedded process where meaning is materialised through language, talk and communication (Weick, Sutcliffe \& Obstfeld, 2005). In this vein, several researchers have examined how entrepreneurs use language in a sensegiving context to influence the way that another party understands or makes sense (Gioia \& Chittipeddi, 1991) of the venture idea, identifying the use of gestures (Cornelissen, Clarke \& Cienki, 2012), metaphors (Nicholson \& Anderson, 2005; Hill \& Levenhagen, 1995), rhetoric and narratives (Holt \& Macpherson, 2010) as communication tools. Whether sensemaking or sensegiving, little 
consideration has been given to the relationship between the entrepreneur and others during this important transition period between venture idea and venture formation. Analysing how these transitions occur (through sensemaking) and the relevant sensegivers (actors) involved is critical to our understanding of venture progression as well as contributing towards a fuller understanding of entrepreneurial action (Mathias, Williams \& Smith, 2015).

In order to understand this transition period, we need to examine those individuals who not only started with an initial insight but also followed through with the decision to exploit that insight as a new venture (Dimov, 2007a). Adopting a sensemaking perspective, the "black box" between venture ideas and venture formation can be explored as new venture ideas arise from the way in which entrepreneurs make sense of their world (Gartner, Carter \& Hills, 2016). We surmise that prospective entrepreneurs utilise sensemaking as a conceptual bridge between venture ideas and venture formation. Accordingly, the research question for this study explores 'how nascent entrepreneurs make sense of venture ideas and transition between ideation and venture formation'. As such, we present a framework that illustrates the entrepreneur's sensemaking during this transition between venture idea and venture formation. In addition to the entrepreneur making sense by filling in their own gaps, they often rely on family members and others in their networks for business advice, emotional support, and business resources (Arregle, Batjargal, Hitt, Webb, Miller, \& Tsui, 2015; Leyden, Link \& Siegel, 2014). The role of other sensegivers in the venture creation process we argue, is pivotal. Thus, we bring the constructs of sensemaking and sensegiving together to offer a new perspective upon the entrepreneurial process, where the focus is not only upon sensemaking and sensegiving but also, on the sensemaking and sensegiving of others within the entrepreneur's support network.

We argue that entrepreneurs are not the only sensegivers during the new venture creation process. Making sense of venture ideas is a social process of discussion and interpretation (Dimov, 2007b); rather than thinking and acting alone, entrepreneurs are actively engaged in the search for knowledge and in value exchanges with a surrounding community (Leyden, Link \& Siegel, 2014; Vaghely \& 
Julien, 2010). Through these exchanges, they gain feedback on their venture ideas to establish them as plausible and convince others of legitimacy, which is an essential, if poorly understood, part of the new venture creation process (Navis \& Glynn, 2011).

The importance of peer feedback during sensemaking has been conceptualised by Wood \& McKinley (2010) who theorised that entrepreneurs either accept or abandon a venture idea through a sensemaking process that takes place between the entrepreneur and others. To our knowledge, this sensemaking process has neither been elaborated upon in the literature, nor empirically researched. In this study, we follow the sensemaking process of entrepreneurs as they transitioned between venture ideas and venture formation and in so doing, elaborate on the ways in which sensemaking unfolds. In addition to analysing sensemaking, we also build upon sensegiving in an entrepreneurial context by highlighting the role of other sensegivers upon the entrepreneurial sensemaking. This addresses contemporary call for future research by Pryor, Webb, Ireland \& Ketchen Jr. (2016) who noted the need for greater understanding of how feedback from network ties can inform entrepreneur conceptualisation and behaviour.

This study offers three contributions. First, we locate the entrepreneurial context as a primary site where sensemaking occurs as it requires entrepreneurs to address the differences between expectations and reality. Second, we show how the transition between venture idea and venture formation requires entrepreneurs to engage in internal sensemaking regarding problem solving causal maps and to be dependent on sensemaking/sensegiving 'exchanges' between the entrepreneur and other sensegivers to refine the venture idea. Finally, we extend scholarly understanding of how entrepreneurial action occurs through explaining the ways in which sensemaking and sensegiving happen in the early stages of venture formation.

The article is structured as follows: In the next section, we review extant research on sensemaking and sensegiving. We then present our methodological approach and thereafter, we discuss our empirically 
grounded findings in relation to entrepreneurship research. Finally, we draw conclusions and consider implications for theory and practice.

\section{THEORETICAL FRAME}

\section{Venture Formation as a sensemaking activity}

The process of forming a new venture is complex, involves nonlinear processes (Garud and Gehman, 2016) and is described by Bhave (1994:223) as "an iterative, nonlinear, feedback-driven, conceptual, and physical process". In earlier research, Gartner (1985:697) theorised that the process of new venture creation could be viewed as the "organizing" of new organisations. Here, Gartner's work reflects Weick's writing in 1979 in the organisational behaviour literature where 'organisation' emerges from a process of sensemaking. Sensemaking is the process individuals undergo when they encounter novel, unexpected, or confusing events (Maitlis \& Christianson, 2014; Weick, 1995). Sensemaking goes beyond interpreting ambiguous events rather it involves the active construction of the very situations that individuals attempt to comprehend (Sutcliffe, 2013; Weick, 1995; Weick et al., 2005). By generalising and institutionalising particular (novel) meanings and rules, we as individuals come to make sense of, or rather, structure our world (Huber \& Daft, 1987; Waterman, 1990).

According to Weick (1995), sensemaking is not only a useful process for reconstructing existing knowledge to make sense of norms, routines and habituated patterns of action but also importantly, for exploring new depths, creating new connections and imagining new kinds of activities (Dougherty, Borrelli, Munir \& O'Sullivan, 2000). We build on the work of Cornelissen and Clarke's (2010) and others (see: Nicholson \& Anderson, 2005; Hill \& Levenhagen, 1995) whose consideration of sensemaking and entrepreneurship were confined to the examination of language (such as analogy and metaphor). In our study, we illustrate that sensemaking can be broader than language and can involve seven other properties (see Weick, 1995), which precede language. 


\section{Operationalising Sensemaking}

Weick (1995) and later Weick, Sutcliffe \& Obstfeld (2005) established eight properties through which sensemaking manifests. First, the establishment and maintenance of identity is a core preoccupation as sensemaking processes are derived from the need within individuals to have a sense of identity - that is "the general orientation to situations that maintain esteem and consistency of one's self conceptions" (Weick, 1995:22). Every individual according to Weick (1995:20) "is a typified discursive construction" meaning that although sensemaking begins with a sensemaker and seems like a singular activity no individual ever acts like a single sensemaker. This is because individual identities are constructed out of a process of interaction with others and to shift among interactions is to shift among definitions of self. In effect, the sensemaker is an ongoing puzzle undergoing continual redefinition, coincident with presenting some self to others and trying to decide which self is appropriate (Weick, 1995). The discovery of who an entrepreneur is, through how and what they think relates to the presentations of others.

The second property follows on from identity in terms of the social interactions between the individual sensemaker and others. As individual identities are constructed from a process of interaction, decision-making occurs either in the presence of others or with the knowledge that these decisions may be implemented, understood or approved by them (Weick, 1995). Individual sensemaking is in part contingent upon others. According to Allport (1985), this contingency holds whether those others are imagined or physically present. Social interactions influence an individual's sensemaking through stereotypical roles, norms and values. However, Blumer (1969:76) argues that while common values and shared meanings are viewed as the "glue" that holds society together, conflicting values are also important because conflict destabilises existing institutional logics causing actors to question "taken-for-granted" assumptions.

This conflict offers an opportunity to either re-establish or break away from the status quo (Weick, 1995). This is of particular relevance when considering the entrepreneurial process as on the one hand, entrepreneurs have been regarded in the entrepreneurship literature as change makers who 
challenge the status quo to create new products, services and possibilities often defying social or institutional norms (Beckert, 1999). On the other hand, entrepreneurs must establish connections to resources and, at some point during the entrepreneurial process, engage with or be affected by relationships with socialising agents (Zimmer, 1986). As such, the entrepreneurial process has been increasingly recognised by scholars as highly contextualised (Welter, 2011) and embedded in social, institutional and locational components (Johnston, Lassalle and Yamamura, 2018). This systemic nature of the entrepreneurial process is captured in the concept of the entrepreneurial ecosystem (Isenberg, 2010; Stam, 2015); the idea that a nurturing and supportive environment can be created for entrepreneurs by developing symbiotic relationships between social networks, government, universities and industry. However, how such ecosystems affect entrepreneurial activity is speculative (Spigel, 2017).

By adopting a sensemaking approach, we embrace both of these ideologies and go a step further to develop a greater understanding of how these socialising agents and symbiotic relationships within social networks impact during the entrepreneurial trajectory. We do so by examining how the sensemaking/sensegiving exchanges between the entrepreneur and others influence the transition between the venture idea and venture formation. Previous research has mainly examined one-way sensemaking/sensegiving between the entrepreneur and others; for example, the creation of a mental model of how the environment works (Hill \& Levenhagen, 1995) and the ability to communicate a meaningful course for a venture to investors/employees (Cornelissen, Clarke \& Cienki, 2012). Our approach is novel in that we focus not only on entrepreneur sensemaking and sensegiving (as in previous studies) but also, on the sensemaking and sensegiving of others in an entrepreneur's support network, which has not yet been fully explored in the literature.

The third and fourth property relate to 'when' sensemaking happens. Weick (1995) initially noted that much of sensemaking is retrospective as individuals assign meaning or 'sense' to their experiences after some action has been taken. However, Weick (1995) also noted that sensemaking is ongoing, where individuals continually rationalise what they are doing and then make sense retrospectively. 
Ongoing sensemaking is often disrupted by discrepancies between expectations and reality. Violations of expectations, either unexpected events or the non-occurrence of an expected event, can vary in magnitude and when the discrepancy between what an individual expects and what is experienced is sufficient enough to raise questions regarding "what is going on?, and what should I do next?" sensemaking is triggered (Maitlis \& Christianson, 2014:70). To make sense of the disruption, individuals look for reasons that will enable them to restore order. These 'reasons' can be pulled from pre-existing frameworks and are materialised through conversing in the social context with other actors (Weick, Sutcliffe \& Obstfeld, 2005).

Framing sensemaking as both ongoing and retrospective is consistent with earlier work by Schroeder Van de Ven, Scudder and Polley (1989) who claimed that sensemaking is preceded by some kind of shock (such as one of necessity, opportunity or threat) which stimulated people's action threshold to pay attention and initiate novel action. Contemporary research on sensemaking and its temporal orientation has further offered the notion of future-oriented prospective sensemaking (Gephart, Topal and Zhang, 2010), involving speculating on and imagining future possible states (Gioia and Mehra, 1996).

For entrepreneurs, as they engage with future possibilities that have yet to come into existence and work to create plausible explanations of a future state in the present, sensemaking can be futureoriented as they work to synthesise multiple potential outcomes of their venture ideas (Cornelissen \& Clarke, 2010). However, Schroeder et al's (1989) claim of preceding shocks is also applicable to the entrepreneurial context as the transition from venture ideas to venture formation has previously been debated in the entrepreneurship literature as dependent on internal or external shocks (Eckhardt \& Shane, 2003; Shane \& Venkataraman, 2003). The entrepreneur's sensemaking therefore, involves cycles of action and cognition as they shift between ongoing, retrospective and prospective sensemaking. 
The fifth property focuses upon what happens during sensemaking. Within an organisational setting, members often encounter moments of ambiguity or uncertainty which trigger their sensemaking. Individual sensemaking according to Weick (1995) involves seeking clarification by extracting and interpreting cues from the environment. These cues form the basis for a plausible account of "what is going on' that provides order and 'makes sense' of what has occurred, allowing individuals to reestablish order and resume acting in the environment (Weick, 1995; Weick, Sutcliffe, \& Obstfeld, 2005). The sense that is made is retained in their minds in the form of cognitive "cause maps" (Sandberg \& Tsoukas, 2015:8). As Weick and Bougon (1986, pp. 102-103) noted, "organisations exist largely in the mind, and their existence takes the form of cognitive maps."

Munoz, Mosey and Binks, provide empirical evidence of such causal maps and how they emerge during the process of entrepreneurship education (Munoz et al, 2011). They found that those students that developed a more sophisticated cognitive map of the entrepreneurial process were subsequently more able to identify a greater number of venture ideas when compared to those students who did not. They concluded that the development of entrepreneurial capabilities appeared intimately related to the development of more sophisticated cognitive causal maps. We argue that entrepreneurs hold their new ventures in their minds in the form of cognitive cause maps, constructed from a collection of cues that entrepreneurs notice and bracket as crucial for carrying out tasks related to the new venture (Sandberg \& Tsoukas, 2015).

The sixth, seventh and eighth properties are concerned with what happens after sensemaking has taken place. Preferably some form of action or as Weick (1979) terms it - enactment - occurs, the results of which individuals subsequently confront as their environment. Individuals are thus, the creators of their own environments; they create the materials that become the constraints and opportunities they face (Weick, 1995:31). In an entrepreneurial context, enactment can take the form of a new product, service, venture or new way of organising (Schumpeter, 1934). The locus of sensemaking as shifting between a cognitive process and a constructive practice (Sandberg \& Tsoukas, 2015) is therefore, evident in an entrepreneurial context. Once enactment has occurred 
individuals are often engaged with producing what Weick (1995) refers to as a "plausible account" or plausibility of their own sensemaking in order to influence the sensemaking of others. For the entrepreneur, this is often the start-up story or retrospective account of the entrepreneurial journey. Finally, because it is through language, talk and communication that individuals influence the sensemaking of others, Weick, Sutcliffe and Obstfeld (2005) later added the eighth property of language as instrumental in sensemaking. As mentioned above, much of the literature on sensemaking in entrepreneurship has captured the eighth property in practice in the form of the entrepreneur's use of metaphors and rhetoric to influence the sensemaking of others (Cornelissen, Clarke \& Cienki, 2012; Holt \& Macpherson, 2010; Hill \& Levenhagen, 1995). Less consideration has been given to the sensegiving of others and how this may influence entrepreneurial sensemaking.

In summary, what remains opaque is how entrepreneurs make sense of venture ideas and translate them into a new venture. In order for this transition to take place a critical evolution unfolds - the entrepreneur has to make sense of "imaginary combinations of product/service offerings, markets, and means of bringing these offerings into existence" (Davidsson, 2015:675). Mainstream research in entrepreneurship is currently focused on venture opportunities, clarifying the ontological status of the opportunity concept (Vogel, 2017; Ramoglou \& Tsang, 2017). However, as we know from prior literature that the venture idea is an important initial moment preceding venture opportunities, we propose new insights can be gained by explaining what happens to venture ideas and how they lead to entrepreneurial action. The entrepreneur's sensemaking/sensegiving 'exchanges' during this transition period can advance our understanding of how the entrepreneur transitions from having a venture idea to venture formation. Consequently, we apply a more comprehensive consideration of the eight properties of sensemaking to explore the role of other sensegivers during these early moments of the new venture creation process to expand upon extant studies (Cornelissen, Clarke \& Cienki, 2012; Holt \& Macpherson, 2010; Hill \& Levenhagen, 1995) that have mainly focused upon the entrepreneur's sensemaking and sensegiving through the use of language in isolation. 


\section{METHODOLOGY AND METHOD}

\section{Research aim}

With the aim of exploring the sensemaking process of transitioning entrepreneurs, we specifically focused on a business incubator, as a site of transition between venture ideas and venture formation. The need to penetrate the cognitive and socially embedded nature of sensemaking made a longitudinal case study of four entrepreneurs in the transition phase a suitable approach due to its ability to develop a situationally grounded understanding and thick descriptions of complex phenomena in their natural setting (Eisenhardt \& Graebner, 2007). The investigation of these complex phenomena in real time made such an approach particularly relevant (Duxbury, 2012; Brundin, 2007).

The case study method enabled 'how' and 'why' questions to be asked in order to understand the nature and complexity (Yin, 2013) of the sensemaking processes taking place. To minimise issues of hindsight bias (Cassar \& Craig, 2009), the case studies were followed over a 12-month period, providing a longitudinal perspective to capture the transition between venture idea and venture formation. Such in-depth qualitative and longitudinal data can delve into the fine-grained, processoriented and experiential aspects associated with this area of study and make a theoretical contribution (Ridder, Hoon and McCandless, 2009). To overcome criticisms of generalisability (Flyvbjerg, 2006) and maintaining researcher reflexivity (Malterud, 2001), we adhered to Eisenhardt's (1989) roadmap for building theory from case study research. This involved a prior specification of constructs, theoretical sampling of cases, within-case analysis and cross-case search for patterns as well as iteratively comparing emergent concepts with extant literature to the point of theoretical saturation. This will be discussed in more detail below.

\section{Case selection}

Nascent entrepreneurs joining the business incubator from November 2012 were identified and selected from the overall database of incubatees as the research population. Of these ten entrepreneurs joining the incubator in November, the venture ideas ranged from complex to simple, enabling within and cross-case analysis (Perry, 1998). The priority was not whether the ten entrepreneurs' ventures 
succeeded but rather, it was important to categorise the different types of sensemaking and sensegiving we observed during the transition period. Purposeful sampling was utilised to select information-rich cases that facilitated theory building around the role of sense-making and sensegiving on the movement between venture idea and formation (Eisenhardt and Graebner, 2007). To maximise the external validity of the study and identify sensemaking approaches that transcend significant contextual variance we present the most diverse four of the ten cases (Van de Ven and Poole, 2002). The four case studies presented in this paper represented the maximum diversity of founder human capital in terms of education, team size, prior entrepreneurial experience and variance in industry sector. Prior studies have shown all of these factors to be influential in the transition from venture idea to venture formation (Arregle et al, 2015, Cassar and Craig, 2009, Lounsbury and Glynn, 2001, Munoz et al, 2011). Table 1 provides an overview of the cases, which have been anonymised.

"Insert Table 1 here"

\section{Data collection}

Data collection consisted of documentary evidence, naturalistic observations and two semi-structured, in-depth interviews conducted with each case nascent enterprise on a longitudinal basis. The first interview was conducted at the outset of the study in November 2012 and no later than January 2013, with the second towards the end of the 9 -12-month period starting around September 2013. Interview questions were framed around the research gaps identified in the literature review as two main themes:

- The process of transitioning between the venture idea and venture formation

-The role of other sensegivers in the venture creation process

A semi-structured interview instrument was developed with a set of open-ended questions (Kvale \& Brinkman, 2009), enabling respondents to "discourse" on the topics (Johannessen, Olaisen and Olsen, 1999:12). Related questions were utilised as prompts, ensuring a more consistent link to the research themes (Poon and Swatman, 1998). The entrepreneur sensemaking questions were structured according to the properties identified from Weick's (1995) and Weick, Sutcliffe \& Obstfeld's (2005) work. Six months in to the study, the respondents were observed at enterprise boot camp training; and 
ten months into the study they were observed again at an enterprise pitching competition. Secondary documentary evidence was collected in the form of business information and literature in order to supplement the longitudinal interview data. Documentary evidence related to the planning and startup of the enterprises, consisting of business plans, proposals, portfolios, press releases, company website materials and promotional videos detailing enterprise background and progression. The documentary evidence enabled the in-depth interviews to concentrate specifically on research themes, while allowing the researcher to build a case history of each nascent enterprise. To ensure the effective development of case histories and the reliability and consistency of this approach, a case study database was created (Darke, Shanks and Broadbent, 1998; Rowley, 2002), which comprised written and electronic notes pertaining to each case, organised and categorised alphabetically. The case study report involved a staged approach in assembling raw data, constructing a case record and narrative (Patton, 1990) organised around the case content categories.

\section{Data analysis}

To provide structure to the analysis, a coding system involving a process of data reduction and verification (Miles, Huberman \& Saldana, 2014) was utilised to categorise the data. We started with the specific a priori constructs related to the research question and existing literature on the sensemaking properties, which were explicitly measured in the interview protocol. Then, we created categories in vivo to maintain the salience and context of relevant chunks of data. There was also some process coding, which became necessary to capture the actions of individuals over time. Thematic analysis was then undertaken moving between the raw data and extant literature on sensemaking to create themes, causal explanations, relationships among actors and theoretical constructs. Table 2 displays the a priori coding used in this research. To minimise confirmatory bias, one author of this paper was not involved in the coding or analysis (Van de Ven and Poole, 2002). To capture entrepreneurial actions we followed Thompson (2009) who defined venture formation as a series of actions with the intent to start a new business, such as forming legal structures, renting space, investing in assets and advertising goods or services. 
"Insert Table 2 here"

Thereafter, the codes were sorted and placed into sections relating to the two research themes developed from the gaps highlighted in the literature. A narrative, interpretivist approach was adopted to enable an accurate description of the data (Corbin, Strauss \& Strauss, 2014). Interpreting which events and experiences were linked to the transition period between venture idea and venture formation was an iterative, extensive process involving multiple reviews by the lead researcher and numerous meetings with the co-authors of this paper in order to explicate and refine the different types of sensemaking and sensegiving happening in each case. Although time-consuming, this was recognised as the most appropriate method to elucidate an agreed meaning from the longitudinal transcripts. The key themes emerging from the coding as being relevant during the transition between venture idea and venture formation are summarised in Table 3. It should be noted that the sensemaking property "identity" was observed in the wider study. However, it is not featured in the table as it was not apparent from the data analysis for this specific research question that the construction of the entrepreneurial identity occurred during the transition period being examined.

"Insert Table 3 Here"

\section{FINDINGS}

Despite the diversity of entrepreneurial experience, founding team size, educational background and industry sector, we found similarities in how the four entrepreneurs used sensemaking and sensegiving to transition from venture ideas to venture formation. This is shown in Figure 1 and is used to structure the subsequent findings section. We found that first, they used sensemaking internally. Here, we saw the entrepreneurs interpreting cues to problematise the venture idea, and then identify the causes of the problem before projecting their venture ideas to sensegivers. We highlight two sensemaking phases that emerged: problem sensing and problem causation. These sensemaking phases were seen to be necessary to reconcile differences between entrepreneur expectations and reality. We discuss how these phases manifest in the cases below. Then, we consider the importance 
of projecting venture ideas to sensegivers, and how these sensegivers influenced the development of the venture idea and subsequent venture creation.

From our analysis we found evidence of entrepreneurs deploying seven of the eight properties of sensemaking (social, cues, retrospective and ongoing, plausibility, language and enactment). In the findings, these properties are shown in italics to highlight where and when they occurred.

We have structured the findings as a series of iterative shifts from sensemaking to sensegiving towards the new concept of sense receiving. We introduce the concept of sense receiving defined as the process through which the respondents received and internalised others' sensegiving about the extent to which the venture idea was novel and satisfied a need in the market. We found that the entrepreneurs did not progress to entrepreneurial action until social interaction with their sensegivers helped to refine the idea until it met these criteria. Ideas that were not found to be novel or meet a market need were abandoned, and the cycle repeated. We observed shifts in entrepreneur's sensemaking rather than a particular order or movement from one property to the next. We propose that some sensemaking properties become necessary at particular points in time and thus, may have more weight than others at any one point in time.

"Insert Figure 1 Here."

\section{Sensemaking Phases}

The following sensemaking phases occurred in succession and were observed as being important in refining the venture idea, often involving multiple iterations and the convergence of phases.

\section{Sensemaking Phase 1: Problem Sensing}

During the transition between the venture idea and the formation of the venture, the respondents first problematised their venture ideas. For example, in the case of Charlie, who wanted to provide broadband internet to disadvantaged groups, the respondent identified a problem, and acknowledged that they had the capability to do something about it. "The opportunity at the moment is around 
broadband...I was always asked even when I was working full time to help friends and family and neighbours if they have a computer problem at home. I'd be the one getting the phone call if the broadband is not working... and you know all I ever got in return was boxes of chocolates and wine and I thought well actually I could charge for doing this". This was also evident in the responses from Bravo, who were aiming to provide a healthy food service, "We identified a gap in the market...because we realised there was no one in the area providing a service like this we thought right well that's a central opportunity".

The identification of a problem and subsequent opportunity to do something about it in the form of a venture idea demonstrates the first sign of sensemaking during the transition between venture idea and venture formation. The respondents noticed a problem, which disrupted their ongoing sensemaking enough for them to stop and sensemake about what was happening i.e. there is a violation in expectations of how things ought to be - whether that is the poor broadband service, or the lack of healthy food service and we also observed the respondents considering what they should do next, in terms of acknowledging a capability to act. The realisation that the problem presented an 'opportunity' or 'central opportunity' suggests future thinking and is a demonstration of prospective sensemaking happening. Using common sense to recognise the problem was identified in each case and labelled as 'problem sensing'. This sensemaking phase then evolved into the subsequent sensemaking phase: problem causation. Supplementary quotes illustrating problem sensing are displayed in Table 4.

\footnotetext{
"Insert Table 4 here"
}

\section{Sensemaking Phase 2: Problem Causation}

In examining how the respondents make sense of venture ideas, we uncovered additional sensemaking during this process. After the initial problem sensing, the respondents retrospectively made sense of the problem by bracketing reasons or causes why the problem existed - hence, problem causation. These reasons or causes of the problem became known to the respondents through their own 
awareness of what was happening around them having actively noticed a problem during their initial sensemaking.

The identification of an underlying cause to the broadband problem was clearly articulated in case Charlie,

“....There is this whole digital divide between the parts of the country that have got good broadband and those that can hardly get a service at all. You only have to go a couple of miles from where I live to be in a white area which is basically you cannot get anything more than dial-up or $3 G$ on a mobile sim. Once you're more than $2 \mathrm{~km}$ from the telephone exchange the broadband signal just peters out"

The bracketing of reasons or causes of the problem demonstrated further sensemaking happening. The identification of causal explanations can be likened to the cognitive "cause" maps (Sandberg \& Tsoukas, 2015:8) that individuals create when they identify cues during individual sensemaking. With the respondents in this study, the causal explanations or cues acted as points of reference for linking their venture ideas to broader networks of meaning and formed the foundation from which a larger sense of what may be occurring could be developed (Weick, 1995).

This is illustrated through the case of Alpha, who was trying to develop a better decorative handkerchief (known as a 'pocket square') where it was emphasised that multiple cues were bracketed as points of reference which served as the foundation from which the venture idea could be developed,

"The squares that we saw available were poor, they didn't match any fabrics we needed and they were too high a price for what they were. Mum was like oh well we'll make one that will look better than that so decided to make one. There have always been pocket squares out there but they've always been of rather poor material ... Someone could charge $£ 30$ in a shop and the fabric would cost them less than a $£ 1$ so they are making a huge margin on it...the founders of Pocket Squares figured if you want something done do it yourself. So, they did!" 
The respondent's cognitive "cause" map was therefore, important in the transition between the venture idea and venture formation. Alpha's causal explanations or cues such as, poor quality, pattern matching and high pricing related to the shortage of quality pocket squares were instrumental in informing a potential solution to the problem. Drawing on such information, the founder believed there was a novel opportunity and refined the abstract venture idea to a substantive ambition to manufacture and sell squares. Consequently, this process of establishing causation observed among all the respondents in this study was labelled as 'problem causation', and considered to be a critical sensemaking phase as it is reliant on the cues property of sensemaking (Maitlis \& Christianson, 2014; Weick, 1995).

\section{Sensemaking/Sensegiving Exchanges}

It is important to note that the respondents did not sensemake in isolation. Rather, the research illustrated that respondents shared their refined venture ideas with others and so attempted to influence the sensemaking of others (Gioia \& Chittipeddi, 1991). The findings indicated that once the respondents made sense of the venture idea internally, i.e. problematising their venture idea (problem sensing) and creating cognitive "cause" maps (problem causation), they attempted to influence the sensemaking of others (sensegiving) by projecting the refined venture idea. This involved asking family and friends about the viability of the idea, as in the case of Bravo, or more formal pitching of the venture idea at business competitions, as in the case of Delta, whose venture aim was to encourage recycling in the community, represented by this quote:

"We first applied to a couple of social enterprise funds thinking there is some mileage in approaching social funds rather than pure commerce but we did not get very much feedback I think possibly because our ideas were still embryonic but also because of the amount of the competition, hundreds applying for the same funds so put it on the back burner then saw the advert for entrepreneurship business competition maybe work better as a business for social good so it did not seem like we compromised on the values of the idea, we tried it, fortunately we won" 
Sensegiving by the respondents to family, friends and potential customers and investors illustrated that sensemaking was happening during the transition between venture idea and venture formation. That respondents approached others to get feedback suggested an awareness that decisions regarding the venture idea required external comprehension and approval (Weick, 1995). In this study, the social property of sensemaking was enacted with others who were physically present. There is also sensemaking happening in terms of creating a plausible account to convince others of the legitimacy of the idea. This was specifically the case of Delta where story-telling around how the business name was derived formed part of the venture idea pitch, "[xy] is a peer-to-peer recycling application that enables individuals and organisations to recycle unwanted items. $x$ - means 'no' and $y$ - means 'throw' it is a bit of a cultural pitch. I'm from the north east, Middlesbrough", and this of course involved the use of language and communication, the eighth property of sensemaking and well documented in the literature on sensegiving and entrepreneurship (Cornelissen, Clarke \& Cienki, 2012; Nicholson and Anderson, 2005; Lounsbury \& Glynn, 2001; Hill \& Levenhagen, 1995).

At this point in the transition between venture idea and venture formation, we observed interesting exchanges between the sensegiving provided by others and the respondents. Our observation went beyond the projection of the venture ideas by the respondents as addressed by, for example, Cornelissen \& Clarke (2010) and Wood \& McKinley (2010). Exchanges between the entrepreneur and third parties remain under explored - particularly with regard to how entrepreneurs make sense of third-party feedback - a process we refer to here as sense receiving.

Sense receiving describes the process through which the respondents received and internalised the sensegiving of others regarding the extent to which the venture idea was novel and satisfied a need in the market (Kirzner, 1997). Of particular note was the value placed upon sensegiving by others in the case, 'Charlie',

"First of all you critically review what you've done yourself based on your own ideas...I call this self-assessment and then you have people who are more expert than you in different things so you might want to call those gatekeepers and you surround yourself by people.... 
and they give you feedback on whether your ideas are feasible and you also assess yourself as to sometimes you might have people telling you no that's not going to work; you've not thought of this; you've not thought of that and so on if you only consider external you might become disillusioned and stifled".

Fundamentally, the sensemaking/sensegiving exchanges enabled the respondents to 'test' their thoughts and ideas. It was this process of externalisation; of utilising sensegivers, which proved extremely useful in developing the venture idea. This was evident in the responses from the founder in case Delta. The objective of the venture was to improve recycling rates in the local community; in developing this idea the value of seeking and internalising feedback was apparent. Yet, it appeared the identity of the sensegiver was not the most significant factor for Delta, but rather, that the sensegiving process took place at all which in itself, enabled respondents to question the stability of their idea.

"It is more than the physical support people can offer it's the fragility of ideas if you cling to it, it dies...you've got to socially ingratiate yourself and we're still sort of tinkering on the edge of that precipice but it is encouraging when other people say they like it".

More importantly, these exchanges with sensegivers went beyond a means of validating the venture idea. The role that sensegivers took within the early moments of the entrepreneurial process was first, a source of feedback to validate the novelty of the idea. Secondary to this, these exchanges also had an unexpected consequence of co-developing the venture idea, through either formal partnership or non-formal sensegiving as discussed below.

\section{Formal sensegiving through partnerships}

We identify a collaborative role of sensegivers in the entrepreneurial process, which goes beyond the provision of advice and support. This collaboration was evident in the case of Delta when a formal partnership was sought with one of their sensegivers. In the case of Delta, the founders realised that the local public authority (local council) were already involved in promoting recycling and so, decided that a partnership would be advantageous. 
"Large organisations like the council...they are already kind of dealing with this area anyway like this reduce recycle is their civic responsibility, so it was a great opportunity to showcase what we've been doing and demonstrate to all the people in the council and try and find someone who would be willing to partner with us. An environmental consultant really interested in sustainable procurement strategies came up to me at the event and said that he was interested in the product and he would commission us to develop the app."

In self-selecting the public authority as one of their sensegivers, the founders projected their venture idea at an event organised by the council and found someone who agreed to the co-development of the mobile app they had designed.

\section{Non-formal sensegiving}

While the other respondents Alpha, Charlie and Bravo did not form formal partnerships, interactions with sensegivers (family, friends, and potential customers), which went beyond receiving feedback, was important in the transition to venture formation. Examples of this informal co-development can be seen from the extract from case study Alpha,

"My family have been a great support to start this venture ...I got all my fashion interest from my mom and my sister (who) did fashion marketing. We put about $£ 4000$ of our own capital into this and dad says he's chair of the board he probes me in the right direction always has monthly meeting with me just to make sure how everything is going on and just leaves me to do it"

In this instance, interactions involved the exchange of tacit knowledge as well as investment from sensegivers in the form of start-up financing. Moreover, whether the sensegiving was formal or informal in the co-development of the idea, what was particularly significant was that these interactions occurred in all cases. In terms of the respondents' sensemaking, the development of partnerships and informal collaborations demonstrate action on the part of the respondents to construct a new reality. Together with others, these respondents have enacted their venture ideas into a new venture. 


\section{DISCUSSION}

In making sense of entrepreneur efforts to transition between venture idea and venture formation, our aim was to understand how the movement between venture idea and venture formation can be explained through a sensemaking lens. Using Weick's theory of sensemaking as a theoretical framing of entrepreneurial activity, we can see that the transition between venture idea and venture formation is an inherently cognitive and socially-situated process. While much sensemaking is routine and unconscious, our use of sensemaking shows how entrepreneurs, in transitioning from venture idea to venture formation, experience disruptions in their sensemaking and shift between sensemaking, sensegiving and sense receiving. The narratives represented an account of how the entrepreneurs made sense of venture ideas and transitioned to venture formation, and how they did this by attending to problems that violated their expectations (sensemaking), sharing their venture ideas with others (sensegiving) and internalising feedback from others (sense receiving).

In the four cases analysed, we interpreted entrepreneurial activity during the transition between venture idea and venture formation as embodying seven properties of sensemaking (social, cues, retrospective and ongoing, plausibility, language and enactment). As noted above, the identity property - while observed in this study - was not included in the findings as it fell beyond our focus in this article. Nevertheless, this echoes Weick's (1995) observation that sensemaking involves the ongoing retrospective development of plausible accounts, derived from the extraction of cues within the social context of other actors, which rationalise what people are doing. Weick's (1995) claims that sensemaking unfolds as a sequence however, has not been observed in this study. As shown in Figure 1, we observed shifts in entrepreneur sensemaking rather than a particular order or movement from one property to the next. We therefore, make a contribution to sensemaking theory suggesting that some sensemaking properties become necessary at particular points in time and thus, may have more weight than others at any one point in time. 


\section{Sensemaking shifts}

The initial sensemaking shift happened through the identification of a problem, which disrupted ongoing sensemaking causing respondents to prospectively speculate about future possibilities they could exploit whilst also retrospectively accounting for the existence of the problem. Although we know that identifying or recognising a problem is a common route followed by entrepreneurs (Kimmitt and Muñoz, 2018), how entrepreneurs decide to prioritise such challenges remains under explored. In exploring entrepreneur sensemaking during the transition between venture idea and venture formation, we conclude that decision-making is based upon the extent to which the problem identified violates expectations about how things ought to be.

The fact that some entrepreneurs sense problems, such as finding a pocket square (decorative handkerchief) while others make sense of recycling initiatives has to do with their threshold for discrepancies between expectations and reality. When the discrepancy between what the respondents expected and what was, in fact, experienced was sufficient to surpass their threshold so, sensemaking about the venture idea was triggered. Thus, we locate the entrepreneurial context as a primary site where sensemaking occurs as it is a visible instance of how actors deal with the non-occurrence of an expected event and go about enacting their expected reality.

The initial sensemaking shift was mostly internal and inherently cognitive. The other sensemaking shift was both cognitive and socially-situated as respondents shifted between sensemaking, sensegiving and sense receiving. Evidence suggests that entrepreneurs attempt to influence the sensemaking of others through various linguistic devices (Cornelissen, Clarke \& Cienki, 2012; Holt \& Macpherson, 2010; Nicholson \& Anderson, 2005; Hill \& Levenhagen, 1995) and peer feedback is important during sensemaking (Wood \& McKinley, 2010), what is less known is how the entrepreneur makes sense of third-party feedback (Pryor et al., 2016). In exploring the entrepreneur's sensemaking during the transition between venture idea and venture formation, we highlight that the entrepreneur is sense receiving - that is, receiving and internalising others' sensegiving. In so doing, 
we extend the work of those such as Wood \& McKinley (2010), who theorise that entrepreneurs either accept or abandon a venture idea through a sensemaking process that takes place between the entrepreneur and his or her peers. We have extended Wood \& McKinley's work with empirical evidence, highlighting shifts in the entrepreneur's sensemaking. We also supplement work on sensemaking/sensegiving in an entrepreneurial context, which predominately focuses on the entrepreneur's sensegiving (Cornelissen, Clarke \& Cienki, 2012; Holt \& Macpherson, 2010; Hill \& Levenhagen, 1995). We have expanded on the use of sensemaking beyond language and highlighted the sensegiving 'exchanges' happening between the entrepreneur and others. These sensegiving exchanges provide empirical justification for the relational dimension of entrepreneurial ecosystems as it illustrates how individual entrepreneurs interact with, and draw upon, a community of interdependent actors (Stam, 2015; Johnston et al., 2018). Furthermore, it reinforces the notion that new venture creation is dependent on the symbiotic relationships that exists within the entrepreneur's networks and that there is a place/space for sensegivers in the entrepreneurial ecosystem.

Our findings also suggest that it is during sense receiving that entrepreneurs deliberate upon the value of the feedback received. This leads to them either moving forward with their venture ideas or becoming disillusioned. Sense receiving therefore, highlights the point at which sensemaking and sensegiving has occurred and entrepreneurial action can begin. Our findings also suggest that it is less important who gives the feedback; rather, that the feedback enables entrepreneurs to distance themselves from the venture idea and in some cases, acknowledge its fragility. As such, we depict the transition between venture idea and venture formation as involving two sensemaking phases and dependent on sensemaking/sensegiving 'exchanges' between the entrepreneur and sensegivers (Figure 1). In so doing, we extend scholarly understanding of how entrepreneurial action occurs through exploring the sensemaking, sensegiving and sense receiving in the early stages of venture formation. 


\section{Limitations and future research}

We acknowledge limitations of our work. First, it is exploratory in nature resulting in a normative model of the sensemaking and sensegiving processes experienced during the entrepreneurial process. Future research is required to consolidate these findings. Second, our study draws heavily on the Weickian sensemaking perspective. Weick's (1995) approach to sensemaking is criticised for its inability to account for issues of power and emotion (Helms Mills, Thurlow and Mills, 2010), and so, is limited in addressing how processes are interpreted and enacted. This limitation opens avenues for future research opportunities on the implications of power and emotions on entrepreneurial action.

\section{Conclusion}

Within this article, we asked: 'how do nascent entrepreneurs make sense of venture ideas and transition between ideation and venture formation?' We argued that research upon the entrepreneurial process, particularly the transition between venture idea and venture formation, can be informed by a consideration of the potential sensemaking and the sensemaking/sensegiving 'exchanges' between the entrepreneur and a diverse range of other individuals. Thus, we have illustrated the importance of such exchanges and how entrepreneurial action depends as much upon these interactions as it does upon individual sensemaking. In illustrating the interactional nature of the entrepreneurial process, we reinforce the relational dimension of entrepreneurial ecosystems as dependent on the symbiotic relationships that exists within the entrepreneur's networks and propose a place/space for sensegivers in the entrepreneurial ecosystem. Our sensemaking analysis illustrates how entrepreneurs in the social context of other actors, whom we refer to as sensegivers, engage ongoing and prospective circumstances from which they extract cues and make plausible sense retrospectively while enacting venture ideas into reality. Accordingly, we argue that the entrepreneurial context is a primary site where sensemaking occurs, particularly through the use of language. We refer to the other sensemaking properties that precede the 'sense made', which then gets communicated through language, and introduce the concept of sense receiving as the culmination of these iterative cycles of 
internal and external sensegiving and sensemaking. Sense receiving is the point at which the entrepreneur is satisfied that the venture idea is novel and meets a market need and, critically, at this point they act, and form a new venture. Thereby, this research has illustrated that the process by which ideas are translated into ventures is an iterative process, which constantly shifts between entrepreneurs and the sensegivers with whom they engage. Only if this iteration between sensemaking and sensegiving occurs and produces recognisable and plausible pathways to action, can the venture emerge. 


\section{References}

Arregle JL, Batjargal B, Hitt MA, Webb JW, Miller T and Tsui AS (2015) Family ties in entrepreneurs' social networks and new venture growth. Entrepreneurship Theory and Practice, 39(2), pp.313-344.

Baumard P (1994) From noticing to making sense: using intelligence to develop strategy. International Journal of Intelligence and Counter Intelligence, 7(1), pp.29-73.

Beckert J (1999) Agency, entrepreneurs, and institutional change. The role of strategic choice and institutionalized practices in organizations. Organization studies, 20(5), pp.777-799.

Bhave MP (1994) A process model of entrepreneurial venture creation. Journal of business venturing, 9(3), pp.223-242.

Brundin E (2007) 11 Catching it as it happens. Handbook of qualitative research methods in entrepreneurship, p.279.

Cassar G and Craig J (2009) An investigation of hindsight bias in nascent venture activity. Journal of Business Venturing, 24(2), pp.149-164.

Corbin J, Strauss A and Strauss AL (2014) Basics of qualitative research. Sage.

Cornelissen JP and Clarke JS (2010) Imagining and rationalizing opportunities: inductive reasoning and the creation and justification of new ventures. Academy of Management Review, 35(4), p.539.

Cornelissen JP, Clarke JS and Cienki A (2012) Sensegiving in entrepreneurial contexts: The use of metaphors in speech and gesture to gain and sustain support for novel business ventures. International Small Business Journal, 30(3), pp.213-241.

Darke P, Shanks G and Broadbent M (1998) Successfully completing case study research: Combining rigour, relevance and pragmatism. Information Systems Journal 8(4): 273-289.

Davidsson P (2015) Entrepreneurial opportunities and the entrepreneurship nexus: A reconceptualization. Journal of Business Venturing, 30(5), pp.674-695.

Dimov D (2007a) From opportunity insight to opportunity intention: The importance of person-situation learning match. Entrepreneurship Theory and Practice, 31(4), pp.561-583.

Dimov D (2007b) Beyond the single-person, single-insight attribution in understanding entrepreneurial opportunities. Entrepreneurship Theory and Practice, 31(5), pp.713-731.

Dougherty D, Borrelli L, Munir K and O'Sullivan A (2000) Systems of organizational sensemaking for sustained product innovation. Journal of Engineering and technology management, 17(3-4), pp.321-355.

Duxbury T (2012) Towards more case study research in entrepreneurship. Technology Innovation Management Review, 2(3).

Eckhardt JT and Shane SA (2003) Opportunities and entrepreneurship. Journal of management, 29(3), pp.333-349.

Eisenhardt KM and Graebner ME (2007) Theory building from cases: opportunities and challenges. Academy of Management Journal, 50(1), pp.25-32. 
Eisenhardt KM (1989) Building theories from case study research. Academy of Management Review, 14(4), pp.532-550.

Flyvbjerg B (2006) Five misunderstandings about case-study research. Qualitative inquiry, 12(2), pp.219-245.

Gartner WB (1985) A conceptual framework for describing the phenomenon of new venture creation. Academy of management review, 10(4), pp.696-706.

Gartner WB, Carter NM and Hills GE (2016) 7. The language of opportunity 1. Entrepreneurship as Organizing: Selected Papers of William B. Gartner, p.218.

Garud R and Giuliani AP (2013) A narrative perspective on entrepreneurial opportunities. Academy of Management Review, 38, 157-160.

Garud R and Gehman J (2016) Theory evaluation, entrepreneurial processes, and performativity. Academy of Management Review, 41(3), pp.544-549.

George G and Bock AJ (2012) Models of opportunity: How entrepreneurs design firms to achieve the unexpected. Cambridge: Cambridge University Press.

Gephart RP Topal C and Zhang Z (2010) Future-oriented sensemaking: Temporalities and institutional legitimation. Process, sensemaking, and organizing, pp.275-312.

Gioia DA and Chittipeddi, K (1991) Sensemaking and sensegiving in strategic change initiation. Strategic Management Journal, 12(6), pp.433-448.

Helms Mills J, Thurlow A and Mills AJ (2010) Making sense of sensemaking: The critical sensemaking approach. Qualitative Research in Organizations and Management: An International Journal, 5(2), 182-195.

Hill RC and Levenhagen M (1995) Metaphors and mental models: Sensemaking and sensegiving in innovative and entrepreneurial activities. Journal of Management, 21(6), pp.1057-1074.

Holt R and Macpherson A (2010) Sensemaking, rhetoric and the socially competent entrepreneur. International Small Business Journal, 28(1), pp.20-42.

Huber GP and Daft RL (1987) The information environments of organizations. In F. M. Jablin, L. L. Putnam, K. H. Roberts, \& L. W. Porter (Eds.), Handbook of organizational communication: An interdisciplinary perspective (pp. 130-164). Thousand Oaks, CA, US: Sage Publications, Inc.

Isenberg DJ (2010) The big idea: How to start an entrepreneurial revolution. Harvard Business Review, 88(6), 40-50.

Johannessen JA, Olaisen J and Olsen B (1999) Strategic use of information technology for increased innovation and performance. Information management \& computer security, 7(1), pp.5-22.

Johnston A, Lassalle P and Yamamura S (2018). Re-conceptualising entrepreneurial ecosystems: a theoretical exploration of evolution over space and time. Geography, Open Innovation and Entrepreneurship, p.221.

Kimmitt J and Muñoz P (2018) Sensemaking the 'social' in social entrepreneurship. International Small Business Journal: Researching Entrepreneurship, p.1 - 28.

https://doi.org/10.1177/0266242618789230. 
Kirzner IM (1997) Entrepreneurial discovery and the competitive market process: An Austrian approach. Journal of Economic Literature, pp.60-85.

Kvale S and Brinkmann S (2009) Interviews: Learning the craft of qualitative research. California, US: SAGE, pp.230-43.

Leyden DP, Link AN and Siegel DS (2014) A theoretical analysis of the role of social networks in entrepreneurship. Research Policy, 43(7), pp.1157-1163.

Lounsbury M and Glynn MA (2001) Cultural entrepreneurship: Stories, legitimacy, and the acquisition of resources. Strategic management journal, 22(6-7), pp.545-564.

Maitlis S and Christianson M (2014) Sensemaking in organizations: Taking stock and moving forward. The Academy of Management Annals, 8(1), pp.57-125.

Malterud K (2001) Qualitative research: standards, challenges, and guidelines. The lancet, 358(9280), pp.483-488.

Mathias BD, Williams DW and Smith AR (2015) Entrepreneurial inception: The role of imprinting in entrepreneurial action. Journal of Business Venturing, 30(1), pp.11-28.

McMullen JS and Dimov D (2013) Time and the entrepreneurial journey: the problems and promise of studying entrepreneurship as a process. Journal of Management Studies, 50(8), pp.1481-1512.

Miles MB, Huberman AM and Saldaña J (2014) Qualitative data analysis: A methods sourcebook. SAGE Publications, Incorporated.

Mills JH (2003) Making Sense of Organizational Change. Routledge, London, UK.

Munoz C, Mosey S and Binks M (2011) Developing opportunity-identification capabilities in the classroom visual evidence for changing mental frames, Academy of Management Learning and Education, Vol.10 (2), pp. 277-295.

Navis C and Glynn MA (2011) Legitimate distinctiveness and the entrepreneurial identity: Influence on investor judgments of new venture plausibility. Academy of Management Review, 36(3), pp.479499.

Nicholson L and Anderson AR (2005) News and Nuances of the Entrepreneurial Myth and Metaphor: Linguistic Games in Entrepreneurial Sense-Making and Sense-Giving. Entrepreneurship Theory and Practice, 29(2), pp.153-172.

Patton M (1990) Qualitative Evaluation and Research Methods (2nd ed.). Newbury Park, CA: Sage.

Perry C (1998) Processes of a case study methodology for postgraduate research in marketing. European journal of marketing, 32(9/10), pp.785-802.

Poon S and Swatman P (1998) Combined-method study of small business internet commerce. International Journal of Electronic Commerce 2(3): 31-46

Pryor C, Webb JW, Ireland RD and Ketchen Jr. DJ (2016). Toward an integration of the behavioral and cognitive influences on the entrepreneurship process. Strategic Entrepreneurship Journal, 10(1), pp.21-42.

Ramoglou S and Tsang EW (2017) Accepting the unknowables of entrepreneurship and overcoming philosophical obstacles to scientific progress. Journal of Business Venturing Insights, 8, pp.71-77. 
Reynolds PD, Carter NM, Gartner WB and Greene PG (2004) The prevalence of nascent entrepreneurs in the United States: Evidence from the panel study of entrepreneurial dynamics. Small Business Economics, 23(4), pp.263-284.

Ridder HG, Hoon C and McCandless A (2009) The theoretical contribution of case study research to the field of strategy and management. In Research methodology in strategy and management ( $p p$. 137-175). Emerald Group Publishing Limited.

Rowley J (2002) Using case studies in research. Management Research News 25(1): 16-27.

Sandberg J and Tsoukas H (2015) Making sense of the sensemaking perspective: Its constituents, limitations, and opportunities for further development. Journal of Organizational Behavior, 36(S1), pp.S6-S32.

Sarasvathy SD, Dew N, Velamuri SR and Venkataraman S (2010) Three views of entrepreneurial opportunity. In Handbook of entrepreneurship research (pp. 77-96). Springer New York.

Schumpeter JA (1934) The theory of economic development: An inquiry into profits, capital, credit, interest, and the business cycle (Vol. 55). Transaction publishers.

Schroeder RG, Van de Ven, AH, Scudder GD and Polley D (1989) The development of innovation ideas. Research on the management of innovation: The Minnesota studies, pp.107-134.

Shane S and Venkataraman S (2003) Guest editors' introduction to the special issue on technology entrepreneurship. Research policy, 32(2), pp.181-184.

Spigel B (2017) The relational organization of entrepreneurial ecosystems. Entrepreneurship Theory and Practice, 41(1), pp.49-72.

Stam E (2015) Entrepreneurial ecosystems and regional policy: a sympathetic critique. European Planning Studies, 23(9), pp.1759-1769.

Thompson E (2009) Individual entrepreneurial intent: construct clarification and development of an internationally reliable metric. Entrepreneurship Theory and Practice. Vol. 33, pp. 669-694.

Vaghely IP and Julien PA (2010) Are opportunities recognized or constructed?: An information perspective on entrepreneurial opportunity identification. Journal of Business Venturing, 25(1), pp.7386.

Van de Ven AH and Poole MS (2002) 'Field research methods'. In Baum, J. A. C. (Ed.), Companion to Organizations. Oxford: Blackwell, 867-88.

Venkataraman S, Sarasvathy SD, Dew N and Forster WR (2012) Reflections on the 2010 AMR decade award: Whither the promise? Moving forward with entrepreneurship as a science of the artificial. Academy of Management Review, 37(1), pp.21-33.

Vogel P (2017) From venture idea to venture opportunity. Entrepreneurship Theory and Practice, 41(6), pp.943-971.

Waterman RH Jr. (1990) Adhocracy: The power to change. Memphis, TN: Whittle Direct Books.

Weick KE (1979) The social psychology of organizing (Topics in social psychology series). Columbus, OH: McGraw-Hill Humanities. 
Weick KE (1995) Sensemaking in organizations (Vol. 3). Sage Publications.

Weick KE, Sutcliffe KM and Obstfeld D (2005) Organizing and the process of sensemaking. Organization Science, 16(4), pp.409-421.

Weick KE and Bougon MG (1986) Organizations as cognitive maps: Charting ways to success and failure. The thinking organization, pp.102-135.

Welter F (2011) Contextualizing entrepreneurship - conceptual challenges and ways forward. Entrepreneurship Theory and Practice, 35(1), pp.165-184.

Wood MS and McKinley W (2010) The production of entrepreneurial opportunity: a constructivist perspective. Strategic Entrepreneurship Journal, 4(1), pp.66-84.

Yin RK (2013) Validity and generalization in future case study evaluations. Evaluation, 19(3), pp.321-332.

Zimmer C (1986) Entrepreneurship through social networks. The art and science of entrepreneurship. Ballinger, Cambridge, MA, pp.3-23. 
Table 1

\begin{tabular}{|c|c|c|c|c|}
\hline Features & ALPHA & BRAVO & CHARLIE & DELTA \\
\hline \multirow{2}{*}{$\begin{array}{l}\text { Industry } \\
\text { sector } \\
\text { Founding } \\
\text { team }\end{array}$} & $\begin{array}{l}\text { Fashion/Clothing } \\
\text { industry }\end{array}$ & $\begin{array}{l}\text { Food/Beverage } \\
\text { industry }\end{array}$ & $\begin{array}{l}\text { Digital } \\
\text { services }\end{array}$ & Digital services \\
\hline & Single entrepreneur & $\begin{array}{l}\text { Two } \\
\text { entrepreneurs }\end{array}$ & $\begin{array}{l}\text { Single } \\
\text { entrepreneur }\end{array}$ & Five entrepreneurs \\
\hline Prior $\mathrm{EE}^{1}$ & No & No & Yes & No \\
\hline $\begin{array}{l}\text { Founding } \\
\text { context }\end{array}$ & $\begin{array}{l}\text { Opportunity } \\
\text { identification }\end{array}$ & $\begin{array}{l}\text { Identified a gap } \\
\text { in the market }\end{array}$ & $\begin{array}{l}\text { Combination } \\
\text { of push and } \\
\text { pull factors }\end{array}$ & $\begin{array}{l}\text { Created technology } \\
\text { to address a need }\end{array}$ \\
\hline $\begin{array}{l}\text { Initial } \\
\text { funding }\end{array}$ & $\begin{array}{l}\text { Family funding and } \\
\text { incubator grant }\end{array}$ & Self-funded & Self-funded & Incubator grant \\
\hline Archival data & $\begin{array}{l}\text { Business plans, } \\
\text { presentations } \\
\text { company website } \\
\text { Press releases, } \\
\text { Imagery }\end{array}$ & $\begin{array}{l}\text { Facebook page, } \\
\text { promotional } \\
\text { videos on } \\
\text { YouTube } \\
\text { Imagery }\end{array}$ & $\begin{array}{l}\text { Business plans } \\
\text { Imagery }\end{array}$ & $\begin{array}{l}\text { Business plans, } \\
\text { consultant portfolio } \\
\text { Press releases, } \\
\text { Imagery }\end{array}$ \\
\hline $\begin{array}{l}\text { Number of } \\
\text { experiences } \\
\text { captured }^{2}\end{array}$ & 37 & 22 & 27 & 21 \\
\hline \multirow{2}{*}{$\begin{array}{l}\text { Internal } \\
\text { informants } \\
\text { External } \\
\text { informants }\end{array}$} & Founder & Both founders & Founder & Two Founders \\
\hline & \multicolumn{4}{|c|}{ Incubation Manager } \\
\hline
\end{tabular}

\footnotetext{
${ }^{1}$ Entrepreneurial experience

2 includes face-to-face interviews; attendance at incubator events
} 
Table 2

\begin{tabular}{|l|}
\hline A PRIORI CODES \\
\hline Idea/Opportunity (the initial thoughts about the product, service or venture) \\
\hline Retrospective/Prospective (how the venture idea came to be noticed) \\
\hline Cues (points of reference forming the basis of what is going on?; cognitive "cause" \\
\hline Venture formation (creation of a new product or venture) \\
\hline Identity (concept of self during the process) \\
\hline Enactment (steps to exploit idea/opportunity involves a series of actions/activities) \\
\hline Language/sensegiving (use of language in conveying the idea/opportunity) \\
\hline Social (use of social networks/ engaging with socialising agents) \\
\hline Ongoing (breaks or disruptions; violations of expectations) \\
\hline Plausibility (efforts to convince others of the idea/ opportunity) \\
\hline
\end{tabular}

Table 4

Supplemental Quotes for Sensemaking Phase 1: Problem Sensing

\begin{tabular}{ll}
\hline Delta & We started thinking about the idea about a year ago and it was \\
& just kind of a conversation in a café on campus about what \\
& we'd like to see as a product, frustrated with a lot of the waste \\
& management services out there. None of the services are \\
& available on mobile and none of them really tap into the kind of \\
& wealth of social information you carry around with you on your \\
& mobile phone...we thought we could probably build something \\
& better. \\
& I have always wanted to set up a business and then an \\
opportunity came round when I had an event I was going to \\
and had to get a pocket square could not find one made one \\
wore it people really liked it so I thought I could start making \\
them
\end{tabular}


Table 3

\begin{tabular}{|c|c|c|c|}
\hline A priori codes & Categories & Themes & Quotes \\
\hline $\begin{array}{l}\text { Idea/Opportunity } \\
\text { (the initial thoughts about the } \\
\text { product, service or venture) }\end{array}$ & $\begin{array}{l}\text { Ideas as problems or gaps in } \\
\text { the market }\end{array}$ & PROBLEM SENSING & $\begin{array}{l}\text { We identified a gap in the market...because we realised there was no one in the } \\
\text { area providing a service like this we thought right well that's a central } \\
\text { opportunity (Bravo) } \\
\text { The opportunity at the moment is around broadband...I was always asked even } \\
\text { when I was working full time to help friends and family and neighbours if they } \\
\text { have a computer problem at home. I'd be the one getting the phone call if the } \\
\text { broadband is not working... and you know all I ever got in return was boxes of } \\
\text { chocolates and wine and I thought well actually I could charge for doing this } \\
\text { (Charlie) }\end{array}$ \\
\hline $\begin{array}{l}\text { Retrospective/Prospective/ Ongoing } \\
\text { (how the venture idea came to be } \\
\text { noticed) }\end{array}$ & $\begin{array}{l}\text { Unmet expectations } \\
\text { Opportunity to solve a } \\
\text { problem }\end{array}$ & SENSEMAKING & $\begin{array}{l}\text { I have always wanted to set up a business and then an opportunity came round } \\
\text { when I had an event I was going to and had to get a pocket square could not } \\
\text { find one made one wore it people really liked it so I thought I could start } \\
\text { making them (Alpha) }\end{array}$ \\
\hline $\begin{array}{l}\text { Cues } \\
\text { (points of reference forming the } \\
\text { basis of what is going on?; } \\
\text { cognitive "cause" maps) }\end{array}$ & $\begin{array}{l}\text { Identified underlying causes } \\
\text { of the problem }\end{array}$ & $\begin{array}{l}\text { PROBLEM } \\
\text { CAUSATION }\end{array}$ & $\begin{array}{l}\text { You get lots of deliveries of pizza, Chinese food and Indian food. There is not } \\
\text { really a healthy product that is delivered at the moment to your door or office } \\
\text { premises (Bravo) }\end{array}$ \\
\hline $\begin{array}{l}\text { Enactment } \\
\text { (steps to exploit idea/opportunity } \\
\text { involves a series of } \\
\text { actions/activities) }\end{array}$ & $\begin{array}{l}\text { Informal collaborations } \\
\text { Partnerships with stakeholders }\end{array}$ & Sensemaking (action) & $\begin{array}{l}\text { An environmental consultant really interested in sustainable procurement } \\
\text { strategies came up to me at the event and said that he was interested in the } \\
\text { product and he would commission us to develop the app (Delta) }\end{array}$ \\
\hline $\begin{array}{l}\text { Language/Plausibility } \\
\text { (use of language in conveying the } \\
\text { idea/opportunity and efforts to } \\
\text { convince others of the idea/ } \\
\text { opportunity) }\end{array}$ & $\begin{array}{l}\text { Pitching the idea at business } \\
\text { competitions } \\
\text { Asking friends and family }\end{array}$ & SENSEGIVING & $\begin{array}{l}\text { We asked family friends what they thought of the idea, if it is viable and they } \\
\text { were like yea makes sense, hasn't been done before and it's quite cool (Bravo) }\end{array}$ \\
\hline $\begin{array}{l}\text { Social } \\
\text { (use of social networks/ engaging } \\
\text { with socialising agents) }\end{array}$ & $\begin{array}{l}\text { Sharing the venture ideas with } \\
\text { others/ } \\
\text { Receiving feedback from } \\
\text { others on the venture idea }\end{array}$ & $\begin{array}{l}\text { PROJECTING } \\
\text { VENTURE IDEAS } \\
\text { SENSE RECEIVING }\end{array}$ & $\begin{array}{l}\text {..You surround yourself by people.... and they give you feedback on whether } \\
\text { your ideas are feasible and you also assess yourself as to sometimes you might } \\
\text { have people telling you no that's not going to work; you've not thought of this; } \\
\text { you've not thought of that ... (Charlie) }\end{array}$ \\
\hline
\end{tabular}




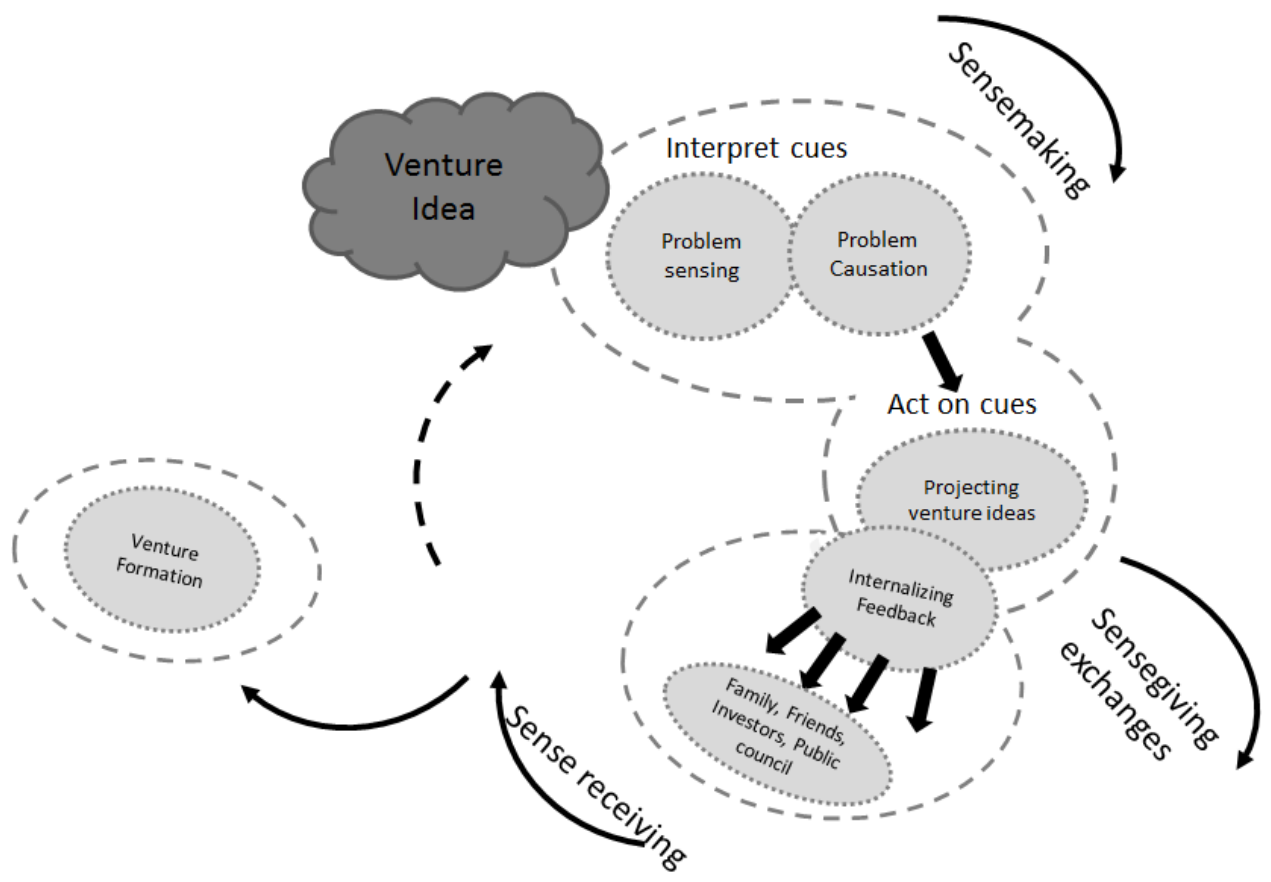

Figure 1 From Venture Idea to Venture Formation: The role of Sensemaking, Sensegiving and Sense receiving 